\title{
Late Presentation of Bronchial Foreign Body in Young Adult: A Case Report
}

\section{Manish V. Jawarkar 1,2*, Saumyasekhar Jenasamant1, Shyamveer Singh ${ }^{3}$, Harpreet Singh Minhas ${ }^{4}$, Muhammad Abid Geelani ${ }^{4}$}

${ }^{1}$ Cardiothoracic and Vascular Surgery (CTVS), G B Pant Institute of Post Graduate Medical Education and Research (GIPMER),

New Delhi, India

${ }^{2}$ Room No. 110, New Resident Doctors Hostel, G B Pant Hospital Campus, New Delhi, India

${ }^{3}$ Cardiothoracic and Vascular Surgery, Artemis Hospital, New Delhi, India

${ }^{4}$ Department of CTVS, G B Pant Institute of Post Graduate Medical Education and Research (GIPMER), New Delhi, India

Email: *manishjawarkar@gmail.com

How to cite this paper: Jawarkar, M.V., Jenasamant, S., Singh, S., Minhas, H.S. and Geelani, M.A. (2016) Late Presentation of Bronchial Foreign Body in Young Adult: A Case Report. Case Reports in Clinical Medicine, 5, 302-307.

http://dx.doi.org/10.4236/crcm.2016.59048

Received: March 24, 2016

Accepted: September 25, 2016

Published: September 28, 2016

Copyright $\odot 2016$ by authors and

Scientific Research Publishing Inc.

This work is licensed under the Creative

Commons Attribution International

License (CC BY 4.0). http://creativecommons.org/licenses/by/4.0/

\begin{abstract}
Foreign body aspiration is common in young children or in adults with advanced age and altered mentation. Usually symptoms present acutely, leading to early intervention. We present a rare case of a healthy young female who aspirated her nasal ring but remained asymptomatic for almost eight years. The patient ultimately required a right upper lobe lobectomy for bronchiectasis.
\end{abstract}

\section{Keywords}

Bronchial, Foreign Body, Lobectomy

\section{Introduction and Review of Literature}

Accidental inhalation of foreign body in children has been known since time immemorial. They present with life threatening symptoms of choking, coughing, wheezing and respiratory distress or go undetected till investigated for frequent upper respiratory infection and persistent cough. Aspiration of foreign body in adults is less common, and usually confined to advanced age or patients with poor dentition, altered sensorium, drug use, etc. One of the largest series published identified 65 adults with tracheobronchial foreign body aspiration over a period of 12 years [1]. A nonasphyxiating foreign body may be asymptomatic. Many of these objects are wedged distally and patients do not often remember choking, the aspiration, or any precipitating event. Thus, foreign body aspiration is commonly misdiagnosed. Diagnosis can be delayed for months to years from the initial event [2] [3], and often results from fortuitous discov- 
ery when fibrobronchoscopy is performed to evaluate a chronic cough, hemoptysis, or a slow resolution of pneumonia. The use of bronchoscopy for foreign body removal was introduced by Gustav Killian in 1897. Currently, both rigid and flexible bronchoscopes are utilized for this indication, depending on the age of the patient and the characteristics of the foreign body. Because of improvement in the accessories used to remove foreign body, survival is good and morbidity is low following bronchoscopic foreign body removal. We report a rare case of accidental aspiration of a nasal ring in a 35-year-old female. The patient had remained essentially asymptomatic for eight years since she first presented with hemoptysis.

\section{Case Report}

A 35-year-old married female presented to us with history of hemoptysis of six months duration. There was no other history of excessive cough or fever. A chest X-Ray (Figure 1\& Figure 2) showed, to our utter surprise, a nasal ring in the upper zone of right lung with evidence of mild bronchiectatic changes in the right lung. On close interrogation, the patient did remember losing this ring about eight years back while asleep at night and had been searching for it since next day morning. The patient was unaware of having aspirated nasal ring as she did not experience any symptoms of choking, coughing or respiratory distress. She remained asymptomatic for next eight years except for occasional episodes of upper respiratory tract infections and fever off and on, which were ignored by her primary care physician.

On admission, a computerised tomography scan of chest was performed, which revealed collapse of right upper lobe with bronchiectatic changes (the CT scan images are however not available).Bronchoscopic removal of the foreign body was attempted but was not successful, as the foreign body was deeply impacted in the right upper lobe. A decision was taken to proceed with right upper lobectomy. The procedure was performed via a standard right postero-lateral thoracotomy. During the procedure, the upper lobe bronchus was encircled and divided carefully to recover the offending ring (Figure 3). The patient had an uneventful post-operative recovery and is doing well on last follow-up which was 6 months after the surgery.

\section{Signs and Symptoms of Inhaled Foreign Body}

The diagnosis of foreign body aspiration can be difficult, especially if the patient does not recall an aspiration episode. Foreign body aspiration has variable clinical manifestations, ranging from trivial symptoms to irreversible lung damage and life- threatening infection, atelectasis, and massive hemoptysis. Patients may present with a history of fever, breathlessness, or wheezing or with features of a non-resolving pneumonia. On physical examination, these patients may have decreased breath sounds on the side with the foreign body or localized wheezing, or they may be asymptomatic. The clinical triad that is considered to be diagnostic of foreign body aspiration consists of wheezing, coughing, and diminished or absent breath sounds.

Complications include: recurrent pneumonias, bronchiectasis, bronchial strictures, 


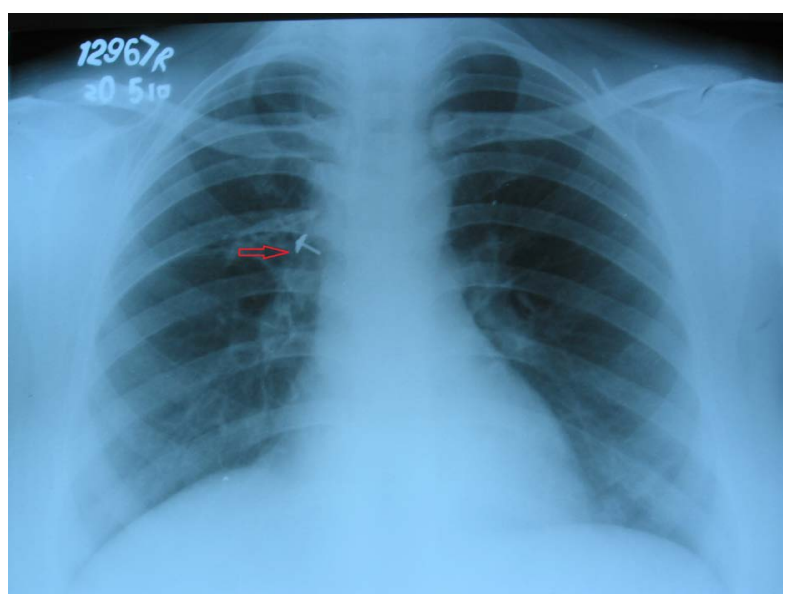

Figure 1. Chest X-ray postero-anterior view showing the retained foreign body in upper zone of the right lung along with bronchiectatic changes in the adjacent lung.

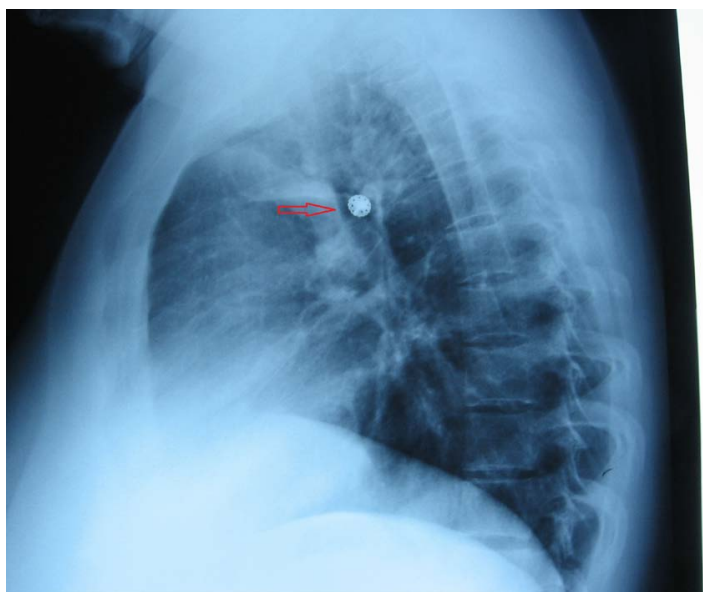

Figure 2. Chest X-ray lateral view showing the retained foreign body.

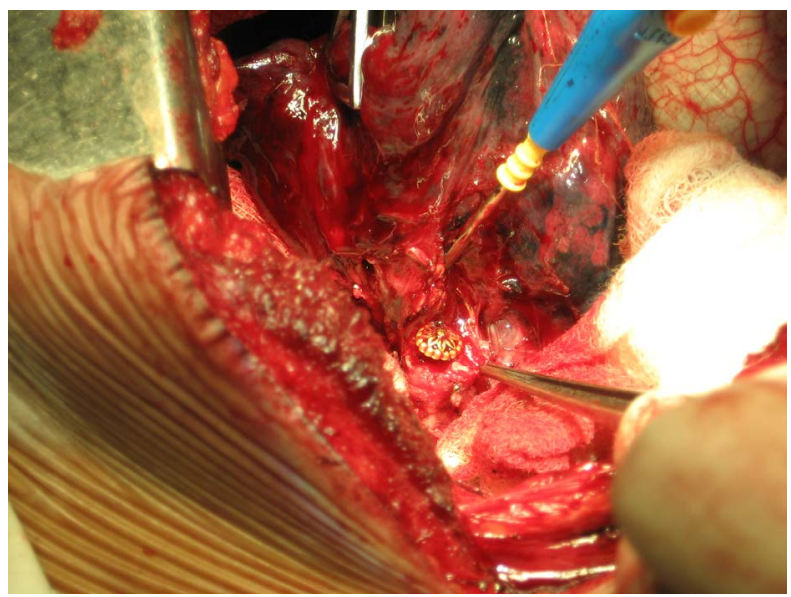

Figure 3. Intra-operative photograph showing the foreign body in the bronchial lumen 
hemoptysis and development of inflammatory polyps at the site of impaction.

\section{Discussion}

Foreign body aspiration refers to the inhalation of solid and liquid material in to the airways. The foreign body may be lodged in to the main bronchus and its branches and may even reach the lungs. The right main bronchus is frequently implicated because of more vertical path. The upper lobe and the superior segment of the lower lobes are thus commonly affected when the patients are in recumbent position. Foreign body aspiration is a common accident in childhood with a high incidence of mortality and morbidity. Children between one to three years of age are more vulnerable [4] [5], due to their lack of dentition and inherent nature to explore their world by putting objects in their mouth. The other age group which is affected by foreign body aspiration is elderly people with poor dentition and with altered sensorium, such as with history of drug or alcohol use. It is extremely rare to find foreign bodies in young healthy adults, as in our case, and that too without producing any apparent symptoms.

Many varieties of foreign bodies may be inhaled, with organic foreign bodies being more common than inorganic (67\% versus 33\%) [6]. The severity of signs and symptoms depend on site, size, composition and duration of lodgement of the foreign body. Organic foreign bodies are more dangerous as compared to metallic ones due to the severe lipoid reaction caused by them. Amongst the inorganic foreign bodies those with sharp edges cause early symptoms. Longer the foreign body stays in the airway, the more likely it is to migrate distally and to give rise to inflammatory reactions, granulation and impaction. This is what happened in our case, because of which bronchoscopic removal was unsuccessful.

Diagnostic imaging plays a variable role. Most of the foreign bodies are not radiopaque. Plain films, therefore, may be fallacious unless they are taken in full expiratory phase. On expiration, air trapping, obstructive emphysema and mediastinal shift may be documented as corroborative evidences. When chest radiograph is normal but suspicion is high helical CT and virtual bronchoscopy can be considered [7].

The rigid bronchoscope remains the gold standard for safe removal of tracheobronchial foreign body [8]. Surgery is very rarely called for. In our case, the only feasible option was a lobectomy as endoscopic removal had failed due to the chronicity of the foreign body and the patient was having hemoptysis due to bronchiectatic changes in the lung.

Informed consent was taken from the patient to report this case. The type of foreign body reported here is not unusual but the course of events is. Often patients have remembered the history of inhalation. However, in our case the patient missed both the in- halation and signs and symptoms of aspiration. Probably inert gold material had minimal tissue reaction and the metallic object allowed the movement of air in the lung without complete obstruction. She did not have any predisposing factors either like advanced age, neurological disorders, alcohol consumption, poor dentition and sedative use [9] [10]. Diagnosis was delayed for eight long years probably due to incomplete ob- 
struction of the airway. Gradually patient may have developed bronchiectatic changes, due to chronic irritation by the foreign body, superimposed with some lower respiratory tract infection which led to delayed presentation with hemoptysis and the ultimate penalty was in the form of lobectomy.

What makes this case unusual is the rather delayed and innocuous presentation after aspiration of such a large foreign object. It emphasizes the fact that healthy adults may tolerate aspiration of foreign bodies for a long time without acute life-threatening consequences. This case shows the importance of further investigation in patients with obstructive airway disease who are unresponsive to routine therapies. Although the diagnosis of foreign body aspiration could be established rather easily in our case due to the radio-opaque nature of the object, this might be particularly difficult in others particularly those with aspiration of radiolucent foreign bodies. The inclusion of foreign body aspiration in the differential diagnosis for such patients allows for early recognition and appropriate management, thereby decreasing the incidence of costly and unnecessary complications. This unusual case emphasizes the need to maintaining a high index of suspicion when an adult presents with chronic complaints of upper respiratory tract infection without any obvious reasons and highlights the need to create awareness about this potentially avoidable situation at the level of general practitioners.

\section{Experience Summary}

In conclusion, bronchoaspiration of foreign bodies by adults is rare. However, it is important to suspect bronchoaspiration of a foreign body in the presence of suggestive symptoms. In adults, respiratory infection (acute or recurrent pneumonia) is the most common clinical presentation. Chest radiography is not always useful for diagnosis. Sometimes metallic foreign bodies can be observed, but other times only indirect signs of alveolar infiltrate are present. Surgical treatment is reserved for cases in which bronchoscopy is unsuccessful or there are irreversible bronchial or lung complications.

\section{References}

[1] Swanson, K.L., Prakash, U.B., McDougall, J.C., Midthun, D.E., Edell, E.S., Brutinel, W.M. and Utz, J.P. (2003) Airway Foreign Bodies in Adults. Journal of Bronchology, 10, 107-111. http://dx.doi.org/10.1097/00128594-200304000-00004

[2] Lan, R.S., Lee, C.H., Chiang, Y.C. and Wang, W.J. (1989) Use of Fiberoptic Bronchoscopy to Retrieve Bronchial Foreign Bodies in Adults. American Review of Respiratory Disease, 140, 1734-1737. http://dx.doi.org/10.1164/ajrccm/140.6.1734

[3] Baharloo, F., Veyckemans, F., Francis, C., Biettlot, M.P. and Rodenstein, D.O. (1999) Tracheobronchial Foreign Bodies: Presentation and Management in Children and Adults. Chest, 15, 357-362.

[4] McGuirt, W.F., Holmes, K.D., Feehs, R. and Browne, J.D. (1988) Tracheobronchial Foreign Bodies. Laryngoscope, 98, 615-618. http://dx.doi.org/10.1288/00005537-198806000-00007

[5] Banerjee, A., Subba Rao, K.S.V.K., Khanna, S.K., et al. (1988) Laryngotracheal Foreign Bodies in Children. The Journal of Laryngology \& Otology, 102, 1029-1032.

http://dx.doi.org/10.1017/S0022215100107170 
[6] Weissberg, D. and Schwartz, I. (1987) Foreign Bodies in Tracheobronchial Tree. Chest, 91, 730-733. http://dx.doi.org/10.1378/chest.91.5.730

[7] Eroglu, A., Kurkcuoglu, I.C., Karaoglanoglu, N., Yekeler, E., Aslan, S. and Basoglu, A. (2003) Tracheobronchial Foreign Bodies: A 10 Year Experience. Turkish Journal of Trauma and Emergency Surgery, 9, 262-266.

[8] Zhang, Y. and Zhang, Z. (2001) Management of Irregular Shaped Airway Foreign Body in Children. Chinese Journal of Otorhinolaryngology, 36, 231-234.

[9] Irwin, R.S., Ashba, J.K., Braman, S.S., Lee, H.Y. and Carrao, W.M. (1997) Food Asphyxiation in Hospitalized Patients. JAMA, 237, 2744-2745.

http://dx.doi.org/10.1001/jama.1977.03270520054024

[10] Rahulan, V., Patel, M., Sy, E. and Menon, L. (2003) Foreign Body Aspiration in Elderly: An Occult Case of Chronic Pulmonary Symptoms and Persistent Infiltrates. Clinics in Geriatric Medicine, 11, 41-43.

\section{Submit or recommend next manuscript to SCIRP and we will provide best service} for you:

Accepting pre-submission inquiries through Email, Facebook, LinkedIn, Twitter, etc. A wide selection of journals (inclusive of 9 subjects, more than 200 journals)

Providing 24-hour high-quality service

User-friendly online submission system

Fair and swift peer-review system

Efficient typesetting and proofreading procedure

Display of the result of downloads and visits, as well as the number of cited articles

Maximum dissemination of your research work

Submit your manuscript at: http://papersubmission.scirp.org/

Or contact crcm@scirp.org 